\title{
Effects of Same-Sided and Cross-Body Load Carrying on the Activity of the Upper Trapezius and Erector Spinae Muscles
}

\author{
Wonh-wee Lee, Ph.D. \\ Department of Physical Therapy, Vision College of Jeonju, South Korea
}

Background The preference of the bag varies according to age, shoulder bag is mostly used by adults. Shoulder bag can result in an asymmetrical load that has negative impacts on the body.

Purpose The purpose of this study was to investigate the effects of same-sided and cross-body carrying on the activity of the upper trapezius and erector spinae muscles in standing position.

Study design Controlled laboratory study, with a pretest-posttest design.

Methods 20 healthy students were asked to carry the shoulder bag, placing it either on a shoulder on the same side of the body as the bag (same-sided load) or in cross-body fashion in standing position. We used surface electromyography to measure the activities of both upper trapezius and erector spinae muscles. We analyzed the data by using paired $t$-test and compared muscle activity in two methods. The alpha level was set at 0.05 .

Results The activity of the right upper trapezius and left erector spinae muscles differed significantly between the two carrying methods $(p<0.05)$, showing significantly less activity under the cross-body condition. The activity of the left trapezius and right erector spinae muscles did not differ significantly between the two carrying methods $(p>0.05)$.

Conclusions We suggest that proper carrying method for shoulder bag is needed to help prevent musculoskeletal pain caused by asymmetrical muscle activity.

Key words Carrying method; Lower back pain; Lumbar rotation syndrome; Shoulder bag; Unilateral load.
Journal of KEMA 2017; 1(1): 2-6 Published Online Dec 30, 2017 pISSN: 2586-4351

Article History Received 31 October 2017 Revised 10 November 2017 Accepted 10 November 2017

\section{CONTACT}

whlee@jvision.ac.kr Wonhwee Lee, Department of Physical Therapy, Vision College of Jeonju, 235 Cheonjam-ro, Wansan-gu, Jeonju-si, Republic of Korea

This is an Open-Access article distributed under the terms of the Creative Commons Attribution Non-Commercial License (http//creativecommons. org/licenses/by-nc/4 0) which permits unrestricted mic permits turestricted non-conmercial use, distribution, and reproduction in any medium, provided the onginal work properly cited.

\section{INTRODUCTION}

People use various types of bags in their daily lives, including backpack, handbag, and shoulder bag. ${ }^{1-3}$ The preference of the bag varies according to age, backpacks are mainly used by children and shoulder bag or handbag are mostly used by adults. ${ }^{2,4}$ The weight of bag acts as an extrinsic asymmetrical load that affects the body's characteristics. ${ }^{5,6}$ When a person carries a shoulder bag over one shoulder, s/he unconsciously changes shoulders and spinal alignment to maintain balance. ${ }^{6,7}$ The spine is deviated la- terally away from the load, and the shoulder is elevated, which increases stress in the lower limb joints and may also affect dynamic balance during gait. ${ }^{6-8}$

Many studies have investigated the effects of asymmetrical loads on posture and muscle activity during gait. ${ }^{1,6,8}$ Asymmetric loads applied to the left side cause a shift in the lumbosacral joint moment dominance to the right side during the left-right single support phase. ${ }^{9}$ Fowler et al. (2006) quantified the kinematics of spine and stature loss induced by carrying an asymmetric load. ${ }^{10}$ A shoulder bag increases the asymmetry of the trunk during gait. ${ }^{11}$ Whittfield et al. 
(2005) reported that asymmetrical loading significantly changes the posture and gait of students and suggested that it may lead to a variety of musculoskeletal complaints such as muscle soreness, back pain, numbness, and shoulder pain. $^{12}$

The previous studies also have investigated the effect of type or weight of bags on posture or muscle activity. ${ }^{12-15}$ According to Al-Khabbataz et al. ${ }^{16}$, the activity of the rectus abdominis muscle significantly increased with an increase in backpack weight, in that a backpack weight of $20 \%$ body weight caused the most significant muscular and postural changes and should be avoided. Phonpichit et al. ${ }^{15}$ found that the activity of the upper trapezius and erector spinae muscles becomes asymmetrical with increments in handbag weight. Continuously carrying a handbag greater than $10 \%$ body weight can cause musculoskeletal problems. At $15 \%$ body weight, lateral pelvic tilt increases, leading to greater movement of the center of the body and a less-efficient gait. ${ }^{13}$

This study focused on the effects of carrying shoulder bag. If a bag is excessively heavy or poorly designed, and depending on how a person carries it, its weight cannot be distributed well, leading to an abnormal posture that affects the musculoskeletal system, causing pain and spinal disorders. ${ }^{17}$ Some studies have compared spinal alignment according to the method used to carry a shoulder bag (samesided vs. cross-body load). ${ }^{2,3,18}$ Ahn (2006) recommended a cross-body carrying method to reduce lateral bending of the spine. ${ }^{2}$ This method also had less overall impact on posture than did a same-sided load. ${ }^{18}$ However, few studies have compared muscle activity in the shoulders and/or back according to carrying method while in a static position. Therefore, the aims of this study was to investigate the effects of same-sided and cross-body carrying on the activity of the upper trapezius and erector spinae muscles in standing position.

\section{METHODS}

The subjects were 20 healthy students (10 males, 10 females) aged (mean \pm SD) $22.3 \pm 2.4$ years, with a height of $168.5 \pm 8.2 \mathrm{~cm}$ and body weight of $60.9 \pm 7.9 \mathrm{~kg}$. All subjects were right-side dominant and did not have any neuromuscular or musculoskeletal dysfunction in any limbs. Before participating in the study, the content and experimental procedures of the study were explained to all subjects. All subjects voluntarily participated in this study and signed an informed consent form.

For the experiment, all subjects used a shoulder bag (40× $7 \times 30 \mathrm{~cm}, 600 \mathrm{~g}$ ) with a single $4 \mathrm{~cm}$ wide strap (Figure 1).

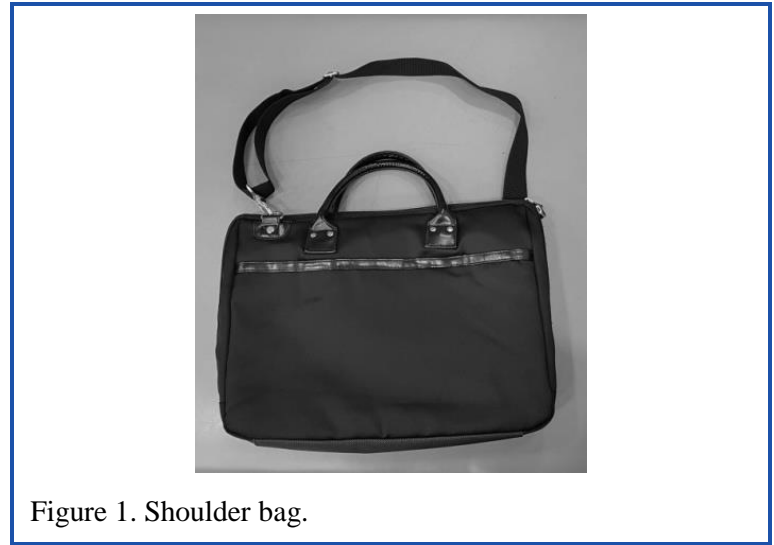

Dumbbells were placed in the shoulder bag to generate a load of $10 \%$ of each subject's body weight. ${ }^{5}$ Each subject was asked to carry the shoulder bag, placing it either on a shoulder on the same side of the body as the bag (samesided load) or in cross-body fashion, adjusting the strap so that the weight sat at hip level. The upper edge of the bag coincided with the iliac crest. ${ }^{2,3}$ All subjects were asked to carry the bag on their right side. When same-sided carrying, the strap of the bag was placed near the acromion of the scapula to prevent it from impacting the activity of the upper trapezius muscle.

Electromyography (EMG) data were collected using the BTS FreeEMG100RT (BTS Bioengineering, Italy) and analyzed using EMG Analyzer software (BTS Bioengineering). A digital band-pass filter (Lancosh FIR) was used to filter movement artifacts $(20-500 \mathrm{~Hz})$. The sampling rate was set at $1,000 \mathrm{~Hz}$. The EMG signals were processed to obtain the root mean square using a moving $50 \mathrm{~ms}$ window. Surface electrodes were fixed at the appropriate sites ${ }^{19}$. To minimize skin resistance, these sites were shaved and cleaned with rubbing alcohol. The electrodes were placed parallel to the upper trapezius and erector spinae muscle fibers bilaterally. For normalization, the mean root mean square of three trials of $40 \mathrm{~s}$ reference voluntary contraction was calculated for each muscle. To measure reference voluntary contraction, the subjects were positioned in a standing position with their arms at their sides without a shoulder bag for $1 \mathrm{~min}$. The first and last $10 \mathrm{~s}$ of data were discarded.

Next, the subjects picked up and carried the bag in either a same-sided or cross-body position (the order was randomized to avoid a systematic postural change that could affect the results), and stood erect with the knees extended and the feet $15 \mathrm{~cm}$ apart in the frontal plane (Figure 2). They held this position for $5 \mathrm{~min}$ (in silence while EMG data were recorded). The first and last minutes of EMG data were discarded. The subjects were allowed to rest in a sitting position for $3 \mathrm{~min}$ between trials and $10 \mathrm{~min}$ between 
Table 1. Comparison of muscle activity according to carrying method

\begin{tabular}{cccc}
\hline Muscle & Carrying method & $\begin{array}{c}\text { Muscle activity } \\
(\% \mathrm{RVC})\end{array}$ & $P$ value \\
\hline Right trapezius & Same-sided & $333.45 \pm 180.07$ & $0.01^{*}$ \\
& Cross-body & $124.60 \pm 43.72$ & 0.89 \\
\hline Left trapezius & Same-sided & $108.85 \pm 25.07$ & 0.08 \\
\hline Right erector spinae & Cross-body & $109.90 \pm 20.78$ & $0.01 *$ \\
\hline Left erector spinae & Same-sided & $91.35 \pm 22.94$ & $81.85 \pm 21.72$ \\
\hline
\end{tabular}

Data are expressed as mean \pm SD.

$* p<0.05$.

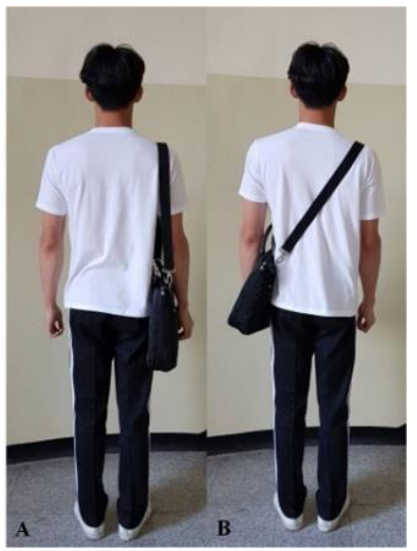

Figure 2. Carrying method of shoulder bag, (A) Same-sided, (B) Cross-body.

two positions to minimize muscle fatigue.

A paired $t$-test was used to examine significant changes in the activity of each muscle. The significance level was set at 0.05. The Statistical Package for the Social Sciences for Window version 18.0 (SPSS, Inc., Chicago, IL, USA) was used for the statistical analyses.

\section{RESULTS}

The activity of the right upper trapezius and left erector spinae muscles differed significantly between the two carrying methods $(p<0.05)$, showing significantly less activity under the cross-body condition. The activity of the left trapezius and right erector spinae muscles did not differ significantly between the two carrying methods $(p>0.05)$ (Table 1)

\section{DISCUSSION}

This study was to investigate the effects of same-sided and cross-body carrying on the activity of the upper trapezius and erector spinae muscles in standing position. Our result showed that same-sided carrying led to excessive activity of the right upper trapezius and left erector spinae muscles. This indicates that carrying a shoulder bag with a same-sided load causes excessive postural isometric contraction of the upper trapezius. ${ }^{20}$ When the upper trapezius is tight, it can compress the greater occipital nerve, which can cause a tension headache. ${ }^{21}$ Such a load can also result in shoulder pain and affect the cervical spine. The samesided carrying and bag weight have a significant correlation with shoulder pain. ${ }^{3}$ The dominance of upper trapezius muscle can affect the cervical spine. ${ }^{22}$ During single arm movement, the dominance of upper trapezius muscle should cause compensatory motion of rotation of a cervical spine segments and produce cervical pain. ${ }^{22,23}$

Our study also demonstrates that the activity of left erector spinae muscle in same-sided carrying is significantly greater than in cross-body condition. These results are also consistent with previous research showing that the activity of erector spinae muscle in unloaded side is increased during same-sided carrying. ${ }^{7,18}$ Overuse of the left erector spinae muscle has a significant impact on the three-dimensional shape of the back, leading to shoulder elevation, a lateral shift of the trunk away from the load, and significantly increased trunk lateral flexion towards the unloaded side. ${ }^{7,10,18}$ These changes may then lead to trunk destabilization and contribute to the development of low back pain. ${ }^{7,23}$

The low back pain was the result of cumulative microtrauma caused by impairments in alignment, in stabilization, and in movement patterns of the spine. ${ }^{22}$ Sahrmann $^{22}$ pro- 
posed that low back pain was diagnosed five categories according to alignment, stress, or movement direction that most consistently produces pain. Among five diagnostic categories, the lumbar rotation syndrome was diagnosed by symptoms with simply rotation or side bending movements and impairments in alignment that is asymmetry of right and left paraspinal area. ${ }^{22}$ Filaire et al. ${ }^{24}$ reported that carrying a unilateral load affected the zygapophyseal joints, which determine the mechanics of spinal rotation and lateral bending. Thus, same-sided carrying could also cause lumbar rotation syndrome by increasing the activity of the unilateral erector spinae muscles.

By contrast, cross-body carrying did not have these effects, probably because when carrying a bag in this way, the center of gravity moves toward the unloaded side, leading to less activity of the right trapezius and left erector spinae muscles. O'shea et al. ${ }^{18}$ also reported that the cross-body load carrying showed depression of the loaded shoulder and extent of lateral shift was lesser than same-sided load condition. During gait, the cross-body load carrying method was also significantly decreased in trunk lateral bending towards the unloaded side compared to same-sided load condition. ${ }^{2}$

Therefore, our results suggest that although bag type and weight can both result in an asymmetrical load that has negative impacts on the body, using a proper carrying method (cross-body carrying) decreases this asymmetry and negative effects. Asymmetric loading can increase energy expenditure, lead to rapid fatigue, and cause progressive postural scoliosis. ${ }^{8,23}$ Therefore, continuous studies on the proper carrying method for different types of bag are needed to help prevent musculoskeletal ailments caused by asymmetrical muscle activity.

This study had several limitations. It was conducted on a small number of healthy students in their 20 s for a brief period of time, and thus we cannot generalize the results to any other group or long period of time. We also did not measure kinematic characteristics. Thus, further studies are needed to investigate the characteristics of the kinematics and kinetics and to analyze long-term effects resulting from different carrying methods.

\section{CONCLUSIONS}

This study compared the activity of the upper trapezius and erector spinae muscles under two methods of bag carrying (same-sided and cross-body). The right upper trapezius and left erector spinae muscles showed significantly less activity during cross-body carrying, suggesting that this method has significantly less impact on spinal posture than does same-sided carrying.

\section{Key Points}

Question What is the proper carrying method for shoulder bag to prevent musculoskeletal disorders?

Findings Carrying a shoulder bag by hanging it on the shoulder on the same side of the body as the bag led to prevent musculoskeletal disorders.

The cross-body carrying method lead to less activity of the right trapezius and left erector spinae muscles, because the center of gravity moves toward the unloaded side.

Meaning Although shoulder bag can result in an asymmetrical load that has negative impacts on the body, using a proper carrying method (cross-body carrying) may be helpful to prevent musculoskeletal disorders caused by asymmetrical load.

\section{Article information}

Conflict of Interest Disclosures: None.

Funding/Support: None.

Acknowledgment: None.

\section{REFERENCES}

1. An DH, Yoon JY, Yoo WG, Kim MH. Comparisons of the gait parameters of young Korean women carrying a single-strap bag. Nurs Health Sci. 2010;12(1):87-93.

2. Ahn JS. The effects of asymmetric load of shoulder bag on trunk and pelvis movement patterns of normal adult during gait. Graduate School of Health and Environment, Yonsei University, 2006.

3. Cho SH, Lee JH, Kim CY. The changes of electromyography in the upper trapezius and supraspinatus of women college students according to the method of bag-carrying and weight. J Phys Ther Sci. 2013;25(9):11291131.

4. Korovessis P, Koureas G, Zacharatos S, Papazisis Z. Backpacks, back pain, sagittal spinal curves and trunk alignment in adolescents: a logistic and multinomial logistic analysis. Spine (Phila Pa 1976). 2005;30(2):247255.

5. Chow DH, Kwok ML, Cheng JC, et al. The effect of backpack weight on the standing posture and balance of schoolgirls with adolescent idiopathic scoliosis and normal controls. Gait Posture. 2006;24(2):173-181.

6. Matsuo T, Hashimoto M, Koyanagi M, Hashizume K. Asymmetric load-carrying in young and elderly women: relationship with lower limb coordination. Gait Posture. 2008;28(3):517-520.

7. Motmans RR, Tomlow S, Vissers D. Trunk muscle activity in different modes of carrying schoolbags. Ergonomics. 
2006;49(2):127-38.

8. Smith B, Ashton KM, Bohl D, Clark RC, Metheny JB, Klassen S. Influence of carrying a backpack on pelvic tilt, rotation, and obliquity in female college students. Gait Posture. 2006;23(3):263-267.

9. DeVita P, Hong D, Hamill J. Effects of asymmetric load carrying on the biomechanics of walking. $J$ Biomech. 1991;24(12):1119-1129.

10. Fowler NE, Rodacki AL, Rodacki CD. Changes in stature and spine kinematics during a loaded walking task. Gait Posture. 2006;23(2):133-141.

11. Yoon JG. Correlations between muscle activities and strap length and types of school bag during walking. $J$ Phys Ther Sci. 2014;26(12):1937-1939.

12. Whittfield J, Legg SJ, Hedderley DI. Schoolbag weight and musculoskeletal symptoms in New Zealand secondary schools. Appl Ergon. 2005;36(2):193-198.

13. Hyung EJ, Lee HO, Kwon YJ. Influence of load and carrying method on gait, specifically pelvic movement. J Phys Ther Sci. 2016;28(7):2059-2062.

14. Negrini S, Negrini A. Postural effects of symmetrical and asymmetrical loads on the spines of schoolchildren. Scoliosis. 2007;2(8):1-7.

15. Phonpichit C, Chansirinukor W, Akamanon C. The response of the body when carrying a handbag. Work. 2016;55(3):673-678.

16. Al-Khabbaz YS, Shimada T, Hasegawa M. The effect of backpack heaviness on trunk-lower extremity muscle activities and trunk posture. Gait Posture. 2008;28(2): 297-302.

17. Whittfield JK, Legg SJ, Hedderley DI. The weight and use of schoolbags in New Zealand secondary schools. Ergonomics. 2001;44(9):819-824.

18. O'Shea C, Bettany-Saltikov JA, Warren JG. Effect of same-sided and cross-body load carriage on 3D back shape in young adults. Stud Health Technol Inform. 2006;123:159-63.

19. Cram J, Kasman G, Holtz J. Introduction of surface electromyography. Gaithersburg. MD: Aspen Publishers, 1988.

20. Muscolino JE. Know the body: Muscle, bone, and palpation essentials. St Louis, Mosby, 2011.

21. Kisner C, Colby LA. Therapeutic exercise: Foundations and techniques. $6^{\text {th }}$ ed. Philadelphia, FA Davis. 2012.

22. Sahrmann SA. Diagnosis and treatment of movement impairment syndrome. New York. USA, Mosby. 2002.

23. Sahrmann SA. Movement system impairment syndromes of the extremities, cervical and thoracic spines. St Louis, Elsevier, 2011.

24. Filaire M, Vacheron JJ, Vanneuville G, et al. Influence of the mode of load carriage on the static posture of the pelvic girdle and the thoracic and lumbar spine in vivo. Surg Radiol Anat. 2001;23(1):27-31. 